\title{
A NOĈ̃O DE SUJEITO NA SEMÂNTICA DO ACONTECIMENTO
} THE NOTION OF SUBJECT IN THE SEMANTICS OF EVENT

\author{
Kelly Cristini GRANZOTTO WERNER ${ }^{1}$ \\ Eliana Rosa STURZA²
}

Resumo: Este artigo tem como objetivo propor uma reflexão sobre a noção de sujeito na Semântica do Acontecimento, proposta e desenvolvida pelo pesquisador brasileiro Eduardo Guimarães, como uma Semântica Histórica da Enunciação. Para tanto, partimos da leitura de duas obras relevantes publicadas por esse autor, a saber: Semântica do Acontecimento: um estudo enunciativo da designação (2002) e Semântica, enunciação e sentido (2018). Numa perspectiva enunciativa, buscamos levar em conta a definição e a caracterização da noção teórica de sujeito, bem como seu lugar e seu funcionamento no interior da referida teoria, compreendendo que trouxe uma contribuição à ciência linguística ao provocar atualizações na forma de conceber tal categoria. Trataremos do funcionamento da noção de sujeito, exemplificando em textos. Como resultado disso, observamos que o sujeito é uma questão linguística e enunciativa, que é agenciado politicamente pelo espaço de enunciação e que mais cabe falar em "lugares enunciativos", "posição", "falante" que, ao enunciar, torna-se três: Locutor (L), locutor (I-X) e Enunciador (E) e "figuras da cena enunciativa" do que em sujeito propriamente. Esse entendimento mostra que ele não é pensado como uma figura una, homogênea e com intenções. Por ser assim considerado na Semântica do Acontecimento, é pouco recorrente a palavra "sujeito" nos livros citados.

Palavras-chave: Sujeito. Enunciação. Semântica do Acontecimento.

\begin{abstract}
The objective of the present article is to discuss the notion of subject in Semantics of Event, proposed and developed by the Brazilian researcher Eduardo Guimarães, as a Historical Semantics of Enunciation. For this purpose, two relevant works by this author have been considered, namely: Semântica do Acontecimento: um estudo enunciativo da designação (2002) and Semântica, enunciação e sentido (2018). From an enunciative perspective, we aimed at taking into account the definition and characterization of the theoretical notion of subject, as well as its place and functioning inside the referred theory, to understand that it has contributed to linguistic science by updating the modes of conceiving such category. The functioning of the notion of the subject is here approached through textual exemplification. As a result, it was possible to observe that the subject is an enunciative and linguistic matter, which is politically managed by the place of enunciation and can be better expressed as "enunciative places", "position", "speaker that, when enunciates, becomes three: Locutor (L), locutor (I-x) and Enunciator (E)" and "figures of the enunciative scene" than solely as the subject. This perception shows that this is not regarded as a unified, homogeneous, and intentional figure. Since this is how it is comprehended in the Semantics of Event, the word "subject" is not very frequent in the mentioned books.
\end{abstract}

Keywords: Subject. Enunciation. Semantics of Event.

1 Universidade Federal de Santa Maria (UFSM), Santa Maria, Rio Grande do Sul, Brasil; kcgbr@yahoo.com.br; https://orcid.org/0000-0002-0681-3999

2 Universidade Federal de Santa Maria (UFSM), Santa Maria, Rio Grande do Sul, Brasil; listurza@gmail.com; https://orcid.org/0000-0003-4085-0096 


\section{Introdução}

Durante muito tempo, pelo menos até a fundação da Linguística Moderna, enquanto ciência, no século XX, por Ferdinand de Saussure, a noção de sujeito pouco interessava aos estudos linguísticos, ficando à margem ou sendo excluída do que era desenvolvido. Posteriormente, com o advento de teorias que compreendem que o sujeito é parte da linguagem e do sentido, essa situação muda, na medida em que passa a importar e a integrar os trabalhos realizados. Em vista disso, nos tempos de hoje, é difícil se pensar em pesquisas na área da Linguística, ignorando a categoria de sujeito pela qual ela perpassa, independentemente da perspectiva teórica adotada e do entendimento dado, e, por isso, interessa. Então, o sujeito aparece apresentado, de diferentes perspectivas, como: falante ideal; sujeito psicológico, que tem intenções, isto é, um usuário; sujeito egocêntrico, responsável pela enunciação e fonte de produção dos sentidos; sujeito da linguagem, que se apresenta como personagens, vozes da enunciação; sujeito ideológico e cindido, que é assujeitado; falante, que se transforma em figuras da enunciação e passa a ocupar ali lugares de fala.

Partindo de uma perspectiva enunciativa, realizaremos um estudo teórico-reflexivo em torno da categoria de sujeito, no interior de uma das correntes teóricas utilizadas como suporte para trabalhos sobre a linguagem, no Brasil, que é a Semântica Histórica da Enunciação (SHE), especificamente, a Semântica do Acontecimento (SA), proposta e desenvolvida pelo professor e pesquisador brasileiro Eduardo Guimarães (2002). Para atingir nosso objetivo, tomaremos como base a leitura de duas obras de grande circulação publicadas por esse autor, a saber: Semântica do Acontecimento: um estudo enunciativo da designação (2002) e Semântica, enunciação e sentido (2018).

No que concerne à metodologia, nosso percurso se organiza em dois momentos principais. Inicialmente, apresentaremos alguns conceitos do quadro teórico da Semântica do Acontecimento a fim de localizar a noção de sujeito no interior desse quadro. A seguir, trataremos da categoria de sujeito, especificamente, refletindo sobre três aspectos: sua definição, suas características e seu funcionamento. Então, faremos a reflexão sobre a inscrição e o funcionamento do sujeito na enunciação a partir dos dois textos citados.

\section{A Semântica do Acontecimento como uma Semântica Histórica da Enunciação}

A Semântica do Acontecimento (SA) foi apresentada por Guimarães, em 2002, na obra Semântica do Acontecimento: um estudo enunciativo da designação. Nessa obra, o autor dedicou-se ao estudo da designação como fundamento para pensar as relações da 
linguagem com o mundo porque, segundo ele, é uma forma de significá-lo e possibilita falar dele. Após percurso de reflexão e análises feitas, passados 16 anos, a teoria aparece reconfigurada no livro Semântica, enunciação e sentido, publicado em 2018.

Essa corrente semântica tem filiação teórica, principalmente, nos estudos semânticos de Bréal (1987), na Teoria da Enunciação de Benveniste (1964, 1965, 1970), na Semântica Linguística e na Teoria Polifônica da Enunciação de Ducrot (1987). Ademais, faz também uma interlocução com a Análise de Discurso, de linha francesa, de onde toma conceitos ou reformula-os, de modo que há aproximações e distanciamentos.

Guimarães (2002) propõe a Semântica do Acontecimento a partir de uma posição materialista, que compreende a linguagem em sua relação com a história. Então, ela não é vista como transparente, definindo-a como "uma semântica que considera que a análise do sentido da linguagem deve localizar-se no estudo da enunciação, do acontecimento do dizer" (GUIMARÃES, 2002, p. 7). Ou, ainda, "uma semântica histórica da enunciação se constitui no lugar em que se trata a questão da significação ao mesmo tempo como linguística, histórica e relativa ao sujeito que enuncia" (GUIMARÃES, 2002, p. 85). Com base nisso, podemos dizer que a Semântica do Acontecimento é uma semântica linguística, é uma semântica da enunciação, ou melhor, uma semântica histórica da enunciação.

Logo, o foco de interesse da SA é fazer um estudo histórico e significativo da linguagem, ou seja, preocupar-se com a questão da significação como algo histórico. Em outras palavras, a significação é determinada pelas condições sociais de sua existência, por sua historicidade, levando-se em consideração como unidade de análise o enunciado, isto é, "como lugar de observação do sentido" (GUIMARÃES, 2002, p. 7) enquanto forma que funciona integrada ao texto. O sentido, então, é visto como uma questão enunciativa e não como algo que está na língua, mas sim no funcionamento dela.

NaSA, a enunciação é entendida como um acontecimento, isto é, "o acontecimento do dizer" (GUIMARÃES, 2018, p. 19), que ocorre pelo funcionamento da língua, pela relação do sujeito com a língua. Para Guimarães (2018, p. 37), o acontecimento é "o que faz diferença na sua própria ordem", entendendo que a diferença está na ideia de que o acontecimento temporaliza, ou seja, instaura a temporalidade de sentidos em torno de si: um passado (memorável), um presente e um futuro (futuridade), que não é cronológica, mas sim simbólica. O acontecimento não é, portanto, um fato no tempo, algo empírico. A atualização da temporalização é importante porque sem ela não haveria sentido, nem acontecimento nem enunciação.

Para que a enunciação se realize enquanto acontecimento de linguagem, são necessários quatro elementos: a língua, o sujeito, a temporalidade e o real, enquanto 
materialidade histórica. Isso mostra que, nessa teoria, o sujeito não é o responsável pela enunciação ou por instalar o tempo no sentido de remeter-se a ele uma centralidade, mas sim o acontecimento, de modo que este ocorre no espaço de enunciação, que é entendido como

[...] o espaço de relações de línguas no qual elas funcionam na sua relação com falantes. Assim não há línguas sem outras línguas, e não há línguas sem falantes e vice-versa. Um aspecto importante na configuração do espaço de enunciação é que as línguas do espaço de enunciação são distribuídas de modo desigual, não se é falante das línguas deste modo da mesma maneira. O espaço de enunciação é, então, um espaço político do funcionamento das línguas. O agenciamento dos falantes, enquanto tal, pelas línguas, é político, pois é necessariamente desigual. (GUIMARÃES, 2018, p. 23-24).

Diante da concepção de enunciação, vemos que o sujeito é uma das categorias importantes para a teoria da SA, mas não é a única nem é a que rege outras categorias como tempo, espaço e sentido. A SA não é, portanto, uma teoria do sujeito.

\section{O sujeito na Semântica do Acontecimento}

Na Semântica do Acontecimento, a palavra "sujeito" é pouco utilizada, embora saibamos que é um dos elementos decisivos para que o acontecimento de linguagem se produza. Por exemplo, nas duas obras utilizadas como base para este trabalho, o referido termo não é tão presente: no livro de 2002, que tem noventa e seis (96) páginas, há quarenta e cinco (45) menções da palavra enquanto, no livro de 2018, que tem 280 páginas, há quarenta e oito (48) registros, sendo quarenta e sete (47) deles usados como parte da oração, sujeito gramatical. Diante disso, cabem alguns questionamentos: como será designado o sujeito? Como ele se apresenta no acontecimento?

Como vimos o sujeito, na SA, não é responsável por colocar a língua em funcionamento ou pela enunciação, tampouco é origem do tempo linguístico. Na verdade, ele é agenciado, constituído pela temporalidade do acontecimento, de tal forma que esse agenciamento é de natureza política ${ }^{3}$ e se dá em um espaço de enunciação

3 Guimarães (2018, p. 50-51) define, em termos enunciativos, o político como algo que "se caracteriza pela oposição entre a afirmação da igualdade em conflito com uma posição desigual do real produzida enunciativamente pelas instituições que o organizam: organizam os lugares sociais e suas relações, identificando-os (ou seja, atribuindo-lhes sentido), e recortam o mundo das coisas, significando-as. Por este conflito o real se divide e redivide, se refaz incessantemente em nome do pertencimento de todos no todos. [...] é a contradição que instala o conflito no centro do dizer". 
específico; sendo assim, o que se tem é falante. Nas obras mencionadas, ao se referir ao sujeito, Guimarães $(2002,2018)$ usa a designação falante e, a partir dele, aborda sua constituição, suas características e seu funcionamento. $O$ falante, ao ser concebido pelo espaço político de enunciação, passa a fazer parte da cena enunciativa, para usarmos a terminologia teórica do autor, e sofre uma divisão que distribui lugares de dizer nessa cena. Dessa forma, esse agenciamento não só é responsável pela distribuição dos lugares enunciativos que o falante ocupa, mas também por aquilo que ele diz, uma vez que não é livre para escolher formas para dizer, nem tem intenções ao dizer, já que são as condições sócio-históricas e políticas que determinam quem diz, como se diz e porque se diz. Nesse aspecto, a SA se distancia de outras semânticas.

Por sua vez, a cena enunciativa, uma categoria metodológica e descritiva na teoria, é produzida pelo agenciamento político da enunciação, ou seja, "o falante é agenciado politicamente e assim constitui a cena enunciativa" (GUIMARÃES, 2018, p. 53), de modo que ela muda a cada acontecimento. Segundo o autor, "é um espaço particularizado por uma deontologia específica de distribuição dos lugares de enunciação no acontecimento" (GUIMARÃES, 2002, p. 23).

Quanto ao falante, Guimarães (2002, p. 18) o compreende como "uma categoria linguística e enunciativa [...] uma figura política constituída pelos espaços de enunciação. E nesta medida ela deve ser incluída entre as figuras da enunciação". Portanto, não é indivíduo, não é pessoa física que fala, mas é o sujeito enquanto constituído e determinado pela relação entre língua e falantes no espaço de enunciação, sendo essa relação litigiosa.

Acerca da situação comunicativa, o falante é agenciado como L, que se representa na enunciação como sua origem, em que a condição necessária para ser L é se dividir no acontecimento. Em outras palavras, significa dizer que precisa ser tomado por um lugar social de dizer, que o autoriza a falar no mundo em determinada língua e de determinada forma. A esse lugar social, Guimarães chamou na obra de 2002 e em trabalhos anteriores de locutor, distinguindo-o, na representação gráfica, com letra minúscula e com a notação $x$, uma variável que corresponde aos papéis enunciativos assumidos (I-x), por exemplo, papel de professor, de jornalista, de cidadão, entre outros. Na obra de 2018, o autor mudou a nomenclatura e alterou a representação, passando a alocutor (al-x). Então, podemos encontrar as duas formas de representar nos trabalhos realizados nessa ancoragem teórica-metodológica. Nesse sentido, vemos que essa figura não é homogênea, porque, para ser L, precisa ser al-x, em que "é preciso que não seja ele próprio, mas um lugar social de locutor". Além disso, o falante ainda pode se dividir mais uma vez, na cena enunciativa, em lugar de dizer, que corresponde ao Enunciador, representado pela letra E. Os lugares de dizer podem ser quatro: individual, coletivo, genérico e universal. 
Quanto ao enunciador individual é um "eu" que tem a ilusão de ser a origem do dizer, pois se esquece (ou desconhece) de que fala de algum lugar e apresenta-se nas formas linguísticas de primeira pessoa e também em marcas avaliativas sobre o que é dito. Segundo Guimarães (2002, p. 25), "é a representação de um lugar como aquele que está acima de todos, como aquele que retira o dizer da circunstancialidade. $\mathrm{E}$, ao fazer isso, representa a linguagem como independente da história".

Já o enunciador coletivo é um nós que fala desde o lugar do conjunto, "que se caracteriza por ser a voz de todos como uma única voz" (GUIMARÃES, 2002, p. 38). Ou seja, o Locutor fala representando um grupo, uma corporação, uma coletividade, podendo, inclusive, na enunciação, apresentar a inclusão do alocutor entre os alocutários.

O enunciador genérico, por sua vez, é um outro lugar de dizer em que o Locutor se mostra como alguém que fala como outros indivíduos, o que pode ser visto nos ditos populares. Há uma simulação por parte do Locutor de ser a origem do dizer, quando, na verdade, diz do lugar do acordo que pode ou não funcionar dependendo da língua, dos falantes e do espaço de enunciação. Há, portanto, um "todos" diluído na indefinição dos provérbios, no discurso do senso comum.

Por fim, tratemos do enunciador universal. Para Guimarães (2002, p. 26), tratase de um "lugar de dizer que se apresenta como não sendo social, como estando fora da história, ou melhor, acima dela. Este lugar representa um lugar de enunciação como sendo o lugar em que se diz sobre o mundo [...] é um lugar que significa o Locutor como submetido ao regime do verdadeiro e do falso". Com isso, quando algo é apresentado desse lugar de enunciação, significa algo posto como universal, verdadeiro, em função do aval da ciência. Então nessa categoria está o discurso científico. No entanto, há um caso que escapa a esse discurso, sendo que o autor cita o seguinte enunciado "Todas as pessoas morrem" (Idem, 2002, p. 26). Ele traz uma máxima afirmativa incontestável que todos sabem que é verdadeira e não provém do discurso científico.

Em resumo, o agenciamento do falante constitui a cena enunciativa e o divide nessa cena em lugares de enunciação, que, como vimos, podem ser três, e instaura, na alocução, seus respectivos correlatos, a saber: Locutor (L) - Locutário (LT), alocutor (alx) - alocutário (at-x), e Enunciador (E) ${ }^{4}$. A figura 1, a seguir, representa o agenciamento enunciativo.

4 "O enunciador não projeta um tu, é um modo de o eu se apresentar na sua relação com o que se diz (o que se diz por quem diz)" (GUIMARÃES, 2018, p. 62). Por isso, na figura, não apresenta correlato. 
Figura 1. Representação das figuras da enunciação na Semântica do Acontecimento

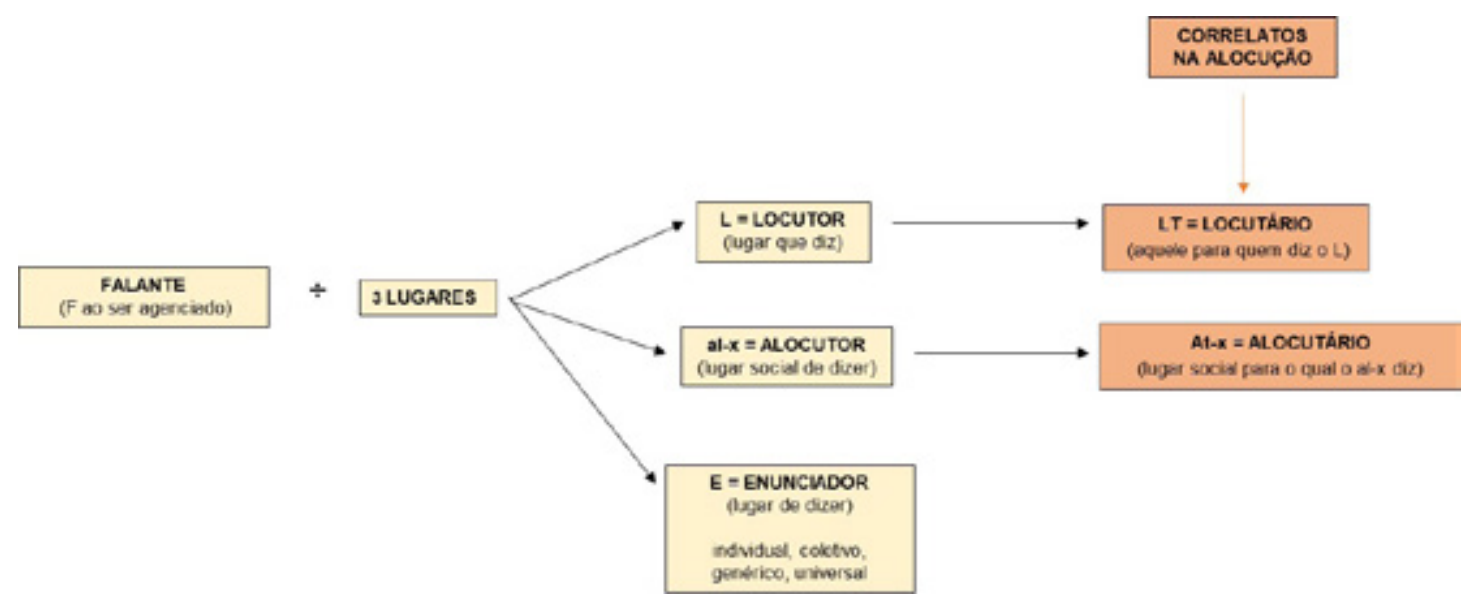

Fonte: Elaboração das autoras a partir de Guimarães (2018)

Porfim, reproduzimos as palavras de Guimarães (2018, p. 71-72) sobre a constituição da cena enunciativa, em função do agenciamento do falante:

A cena enunciativa se constitui pelo agenciamento do falante a dizer. $\mathrm{O}$ agenciamento do falante o divide na cena em lugares de enunciação: o daquele que diz (Locutor), o lugar social de dizer (alocutor), e o lugar de dizer (enunciador). Esta divisão dos lugares de enunciação constitui o que chamamos aqui de politopia da cena enunciativa. A cena enunciativa não configura, nesta medida, um lugar central que subsume os outros lugares. Estes lugares relacionam-se uns aos outros, pela apresentação que o alocutor e o Locutor fazem dos outros lugares ou pela alusão de um lugar ao outro.

Para ver o agenciamento enunciativo em funcionamento, trazemos exemplos em textos sobre a temática do movimento de professores de espanhol, que reivindicam a permanência legal da disciplina de Língua Espanhola na Educação Básica brasileira, a qual nasceu no Rio Grande do Sul e se expandiu, contando com representantes em todos os Estados do Brasil, após a revogação da Lei 11.161/2005, pelo então presidente da República Michel Temer, em 2017. Essa lei assegurava a obrigatoriedade da oferta do espanhol no Ensino Médio e opcional no Ensino Fundamental. A designação $0^{5}$ do movimento é "\# Fica espanhol" e surge na antonímia das designações que se produzem em "Fora espanhol" ou "Sai espanhol" dos currículos escolares. Essa designação passa ter um significado nesse

5 Compreendemos a designação conforme Guimarães $(2002,2018)$. 
- A noção de sujeito na Semântica do Acontecimento

jogo de forças que se instaurou a partir das condições sócio-históricas e políticas de seu aparecimento no acontecimento enunciativo. Segundo Moreno (2019, p. 72, tradução nossa ${ }^{6}$ :

A notícia da revogação da Lei 11.161 não produziu, portanto, implicações apenas para os professores: os estudantes também se sentiram envolvidos nas mudanças que isso provocaria e ainda se sentiram prejudicados nos seus direitos e aspirações em relação à língua. É, nesse cenário, que surge o movimento "Fica Espanhol", reunido nas redes sociais sob \#FicaEspanhol.

A partir dessa discussão acerca da disciplina de língua espanhola, os textos que selecionamos fazem parte de campanhas, depoimentos e manifestações de apoio que circulam principalmente no universo da internet. A Figura 2 traz o primeiro exemplo textual para observarmos o funcionamento das figuras da enunciação.

Figura 2. Primeiro exemplo

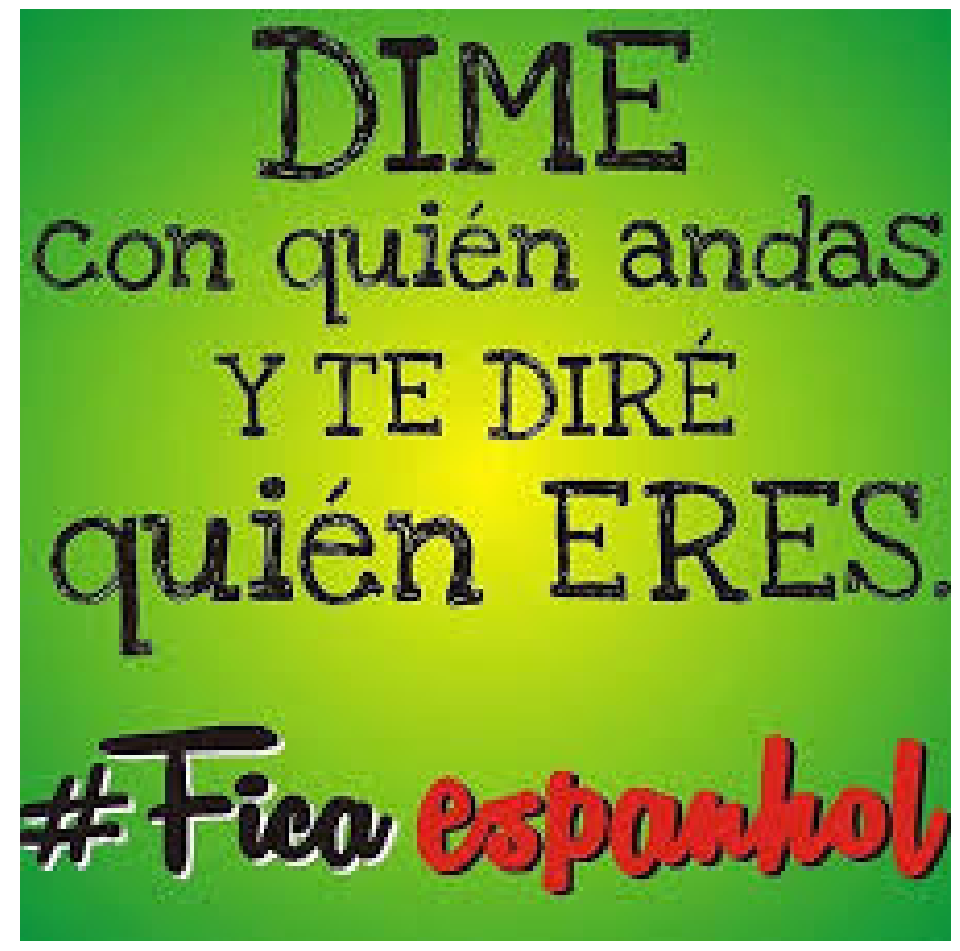

Fonte: https://www.picuki.com/media/2186765312524192640

6 No original: "La noticia de la revocación de la Ley 11.161 no produjo, por lo tanto, implicaciones apenas para los profesores: los estudiantes también se sintieron implicados en los cambios que eso provocaría e, además, se sintieron dañados en sus derechos y aspiraciones con relación a la lengua. Es en ese escenario que surge el movimiento 'Fica Espanhol', reunido en las redes sociales bajo \#FicaEspanhol.". 
Nesse primeiro exemplo, há o agenciamento do falante em Locutor, que toma a palavra desde o lugar social de alguém que conhece e trabalha com a língua espanhola, ou seja, um alocutor-professor, autorizado a falar nessa e sobre essa língua e dessa maneira. $\mathrm{Na}$ cena enunciativa, o alocutor apresenta o dizer como coletivo no enunciado "\#Fica espanhol", pois representa o grupo de professores de espanhol. Mas vemos também que esse enunciador não é o único no texto, havendo uma alusão a um enunciador genérico em "Dime con quién andas y te diré quién eres", que é um dito popular. Sendo assim, o Locutor ora manifesta o dito como a voz do grupo de manifestantes, ora como a voz de um "todos", difusa numa indefinição.

Observemos, agora, a Figura 3, que traz o segundo exemplo de texto a ser analisado.

Figura 3. Segundo exemplo

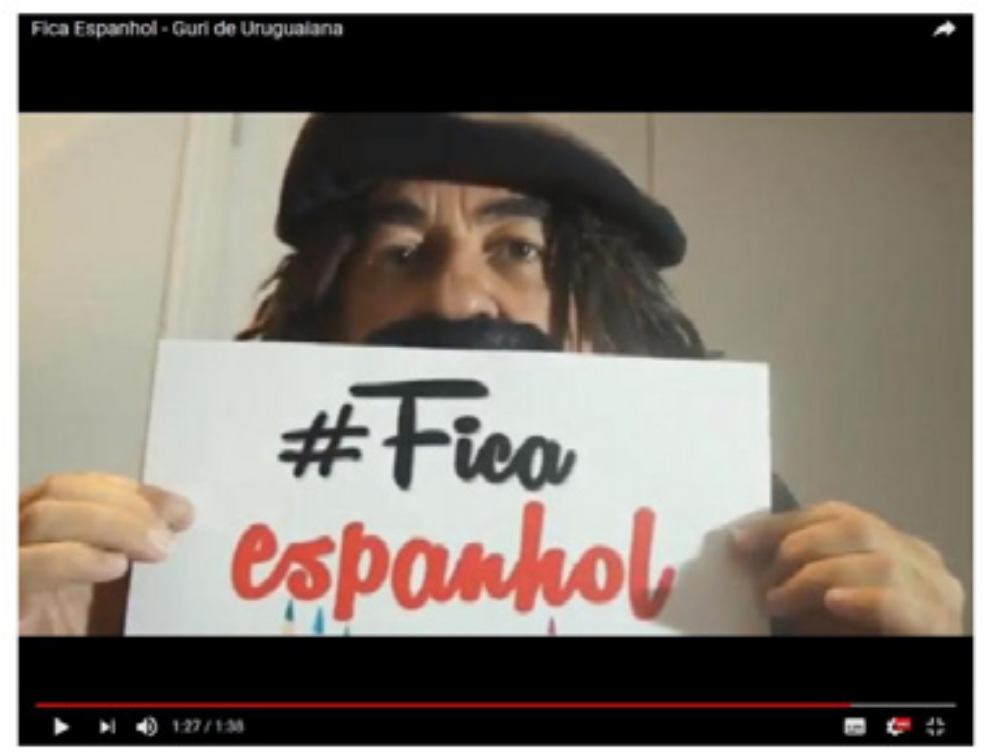

Fonte: https://gauchazh.clicrbs.com.br/educacao-e-emprego/noticia/2018/09/ficaespanhol-

conquista-a-primeira-vitoria-na-assembleia-legislativa-cjly5p8nj02gr01pxpldl4ynw.html

A figura 3 traz o depoimento de um artista na forma audiovisual que aparece no interior de uma reportagem na modalidade escrita e publicada no jornal Zero Hora/ RS, do dia 19/07/2018, sob a autoria da repórter Aline Custódio. Trata-se de um texto que se relaciona com outro texto cujo título é "\#Ficaespanhol: movimento ganha força no RS após lei alterar ensino de idiomas nas escolas". O texto que nos interessa também está no YouTube e traz o depoimento de um artista gaúcho, conhecido como "Guri de Uruguaiana", demonstrando apoio ao movimento no Estado do Rio Grande do Sul (RS). 
Nesse depoimento, observarmos o que é dito na imagem e também o que é dito oralmente no vídeo integradamente. Transcrevemos o último trecho do enunciado oral, que diz o seguinte: "Se tu é gaúcho, tu tem que conhece o espanhol, tem que conhece a cultura e a língua dos nossos vizinhos, né chê. É por isso que eu, o Guri de Uruguaiana, também apoio Fica Espanhol".

Ao dizer que apoia, o "Guri de Uruguaiana" ergue o cartaz que tem nas mãos, o qual podemos ver na imagem anterior. Nesse texto, o falante agenciado em Locutor toma a palavra não mais do lugar social de professor, mas sim do lugar de artista gaúcho, o qual o autoriza a falar, como um personagem que vive num Estado brasileiro fronteiriço aos países de língua espanhola. A apresentação do seu dizer de apoio é feita por uma voz individual, marcada no último enunciado "É por isso que eu, o Guri de Uruguaiana, também apoio 'Fica Espanhol'". Ou seja, o enunciador individual diz em primeira pessoa "eu, apoio" e também por seu nome "Guri de Uruguaiana", colocado como um aposto especificativo do "eu" que o antecede, de modo que ele se torna responsável por todo o enunciado, mas não pela expressão "Fica Espanhol", a qual ele apenas repete.

Agora, se olharmos o enunciado da imagem isolado de seu texto oral, poderíamos interpretar da seguinte forma a cena e o agenciamento enunciativo: o falante toma a palavra como o Guri de Uruguaiana, um artista, que diz algo por escrito, "\#Fica espanhol", de uma perspectiva que é individual, em que poderíamos parafrasear, dizendo: Eu, Guri de Uruguaiana, peço: Fica espanhol". Isso quer dizer que poderíamos atribuir o enunciado do cartaz, na imagem, a um enunciador individual, e não mais uma alusão a um dizer originado na coletividade, no movimento.

Diante do que vimos, a Semântica do Acontecimento não permite pensar na noção de sujeito como uma categoria centrada em uma unidade, porque ela não se apresenta dessa forma. Para essa assertiva, os textos trazidos para análise exemplificam o agenciamento das figuras da enunciação e seu movimento de dispersão.

\section{Considerações finais}

Diante de tudo o que foi discutido e analisado neste artigo, nossa reflexão nos leva a ver que a Semântica do Acontecimento, praticada no Brasil, por Eduardo Guimarães (2002, 2018) e estudiosos dessa corrente teórica, não se mostra como uma teoria da subjetividade, e sim uma teoria que se ocupa do estudo da significação como algo que está no funcionamento da língua, na enunciação como acontecimento. Todavia, isso não quer dizer que o sujeito não interessa, apenas que não é o centro de suas atenções. 
Diante disso, observamos que o sujeito é uma questão linguística e enunciativa, que é agenciado politicamente pelo espaço de enunciação, de tal modo que mais cabe falar em "lugares enunciativos" ou "posição" ou "falante que, ao enunciar, torna-se três: Locutor (L), alocutor (al-x) e Enunciador (E)" ou "figuras da cena enunciativa" do que em "sujeito" propriamente. Esse entendimento mostra que ele não é pensado como uma figura una, homogênea e com intenções, mas sim como uma tripla noção. Nesse sentido, concordamos com Steigenberger et al. (2011, p. 71), quando afirma que "não se fala em sujeito na SHE, fala-se em "disparidade do sujeito" (um único personagem disparizado em três faces: L, l e E)". Em assim sendo concebido, é possível compreendermos porque a palavra "sujeito" é pouco recorrente nas duas obras utilizadas como base para este artigo e também para as análises que são feitas a partir desse suporte teórico-metodológico.

\section{Referências}

BENVENISTE, É. Os níveis da análise linguística. In: BENVENISTE, É. Problemas de Linguística Geral I. Tradução Maria da Glória Novak e Maria Luisa Neri. 4. ed. Campinas: Pontes, 1995 [1964]. p. 127-149.

BENVENISTE, É. O aparelho formal da enunciação. In: BENVENISTE, É. Problemas de Linguística Geral II. Tradução Eduardo Guimarães et al. Campinas: Pontes, 1989 [1970]. p. 81-92.

BENVENISTE, É. A linguagem e a experiência humana. In: BENVENISTE, É. Problemas de Linguística Geral II. Tradução Eduardo Guimarães et al. Campinas: Pontes, 1989 [1965]. p. 68-80.

BRÉAL, M. Ensaio de semântica: ciência das significações. Tradução Eduardo Guimarães et al. 2. ed. Campinas: Editora RG, 2008.

DUCROT, O. Esboço de uma teoria polifônica da enunciação. Tradução Eduardo Guimarães. In: DUCROT, O. O dizer e o dito. Campinas: Pontes, 1987. p. 161-218.

GUIMARÃES, E. Semântica, enunciação e sentido. Campinas: Pontes editores, 2018.

GUIMARÃES, E. Semântica do acontecimento: um estudo enunciativo da designação. Campinas: Pontes, 2002a. 
- | A noção de sujeito na Semântica do Acontecimento

GUIMARÃES, E. Os limites do sentido. Um estudo histórico e enunciativo da linguagem. 2. ed. Campinas: Pontes, 2002b [1995].

MORENO, A. B. A. La enseñanza de lengua española en Brasil: historia, legislación, resistencias. Iberoamérica Social: Revista-red de estudios sociales, Sevilla, v. XIV, p. 61-79, 2019. Disponível em: https://iberoamericasocial.com/wp-content/ uploads/2019/12/Moreno-A.-2019.-La-ense\%C3\%B1anza-de-lengua-espa\%C3\%B1ola-enBrasil.-Historia-legislaci\%C3\%B3n-resistencias.pdf. Acesso em: 5 set. 2020.

STEIGENBERGER, F. F.; MACHADO, J. C.; SILVA, S. S. Fronteira entre análise de discurso e semântica histórica da enunciação: abordagens teóricas. Revista de Estudos da Linguagem, Belo Horizonte, v. 19, n. 2, p. 51-79, jul./dez. 2011. Disponível em: http://www.periodicos.letras.ufmg.br/index.php/relin/article/view/2563. Acesso em: 10 fev. 2020.

COMO CITAR ESTE ARTIGO: GRANZOTTO WERNER, Kelly Cristini; STURZA, Eliana Rosa. A noção de sujeito na semântica do acontecimento. Revista do GEL, v. 18, n. 1, p. 56-67, 2021. Disponível em: https://revistadogel.gel.org.br/

Submetido em: 07/12/2020 | Aceito em: 23/01/2021. 